\title{
Nanoparticles targeted drug delivery system via epidermal growth factor receptor: a
} review

\author{
Agus Rusdin ${ }^{1,6}$, Nasrul Wathoni ${ }^{1, *}$, Keiichi Motoyama², I Made Joni³, Ronny Lesmana ${ }^{4}$, \\ Muchtaridi $^{5}$
}

1. Department of Pharmaceutics and Pharmaceutical Technology, Faculty of Pharmacy, Universitas Padjadjaran, Sumedang 45363, Indonesia

2. Graduate School of Pharmaceutical Sciences, Kumamoto University, Chuo-ku, Kumamoto 862-0973, Japan

3. Department of Physics, Faculty of Mathematics and Natural Sciences, Universitas Padjadjaran, Sumedang 45363, Indonesia

4. Department of Anatomy, Physiology and Biology Cell, Faculty of Medicine, Universitas Padjadjaran, Sumedang 45363, Indonesia

5. Department of Pharmaceutical Analysis and Medicinal Chemistry, Faculty of Pharmacy, Universitas Padjadjaran, Sumedang 45363, Indonesia

6. Department of Pharmacy, Faculty of Sports and Health, Universitas Negeri Gorontalo, Gorontalo 96128, Indonesia

Received: 12 Sep 2019/ Revised: 18 Sep 2019/Accepted: 18 Sep 2019/Published: 1 Oct 2019

\begin{abstract}
Overexpressing of epidermal growth factor receptor (EGFR) in specific organ implicates tumour aggression and proliferation. Therefore, EGFR becomes a primary consideration for targeted cancer therapy. Nanoparticle drug delivery system is a promising multifunctional technique to provide the targeted drug delivery system. This review was aimed to discuss the nanoparticles formulation for targeted drug delivery system via EGFR. The data were collected from published journals recorded in the Scopus database, with 27 and 33 journals as primary and supporting literatures respectively. Various types of nanoparticles were widely studied to provide an EGFR-targeted drug delivery system. The formulations using specific targeting mediators were conjugated on several technologies such as polymeric nanoparticles, nanometals, and miscellaneous nanoparticles. Most of nanoparticle formulations become an excellent delivery carrier for drugs or gene to site-specific targeted by in vitro and in vivo evaluations. EGFR-targeted drug delivery system could be a promising technique to provide high effectiveness of drugs in EGFR-positive cells cancers with lower side effects to non-tumour cells.

Keywords: Epidermal growth factor receptor, Cancer, Nanoparticle, targeted drug
\end{abstract}

\section{Introduction}

Epidermal growth factor receptor (EGFR), one of the human epidermal receptor (HER1), includes in the family of receptor tyrosine kinases. The receptor is consist of a single chain transmembrane of glycoprotein, an extracellular ligand-binding domain, a transmembrane region, and an intercellular tyrosine kinase domain [1-2]. The EGFR has a multifunctional and responsible for several cell regulations such as proliferation, growth factor, differentiation, and programmed cell death (apoptosis). Also, EGFR plays an important role in cancer cells progression, formation, metastasis, and angiogenesis [3-5]. It has been proved as a specific characteristic of several cancer cells, which is indicated by EGFR overexpressed on surface cells membrane. These cells are known as an EGFRpositive cell, as signalling for several types of cancer, such as breast cancer, colorectal cancer, pancreatic cancer, colon cancer, glioblastoma, gastroesophageal cancer, nasopharyngeal cancer, bladder cancer, ovarian cancer, head and neck squamous cancers, and non-small cell lung cancer (NSCLC) [616]. Therefore, EGFR becomes a primary 
consideration for drug targeted in the clinical treatment of cancer diseases. In previous studies, EGFR targeted drug delivery system was provided by many approaches, including anticancer drugs combination therapy with targeting mediators and complex formulation mediated by nanoparticle-targeted drug delivery system [17-19]. In the last decade, nanoparticle drug delivery systems become an excellent modification approach and the most commonly studied for the development of diseases treatment. Its multifunctional capabilities become a fundamental reason for this system to resolve physicochemical properties of the drug, such as solubility, penetration rate and bioavailability problems. It also provides a controlled release and targeted delivery in specific cell or organ, which leads for anti-cancer drug delivery [20-22]. The primary problem of anticancer drugs generally has a poor site selectivity which causes a side effect to non-cancer cell [23]. Therefore, a nanoparticle targeted drug delivery system become an alternative technique to resolve this site selectivity problem. Many studies of nanoparticle-targeted drug delivery system have been proved to work correctly as a delivery carrier onto gene targeting, enzyme and receptor-like an EGFR targeted drug delivery system.

Studies of EGRF targeted drug delivery system have been published and recorded in the Scopus database. However, it was limited to discuss its therapy agents (single/combination), strategies, resistance, pharmacogenomics, mechanism, detection methods of EGFR mutations and there were no studies focussing on EGRF targeted mediated by nanoparticle formulation [24-28]. Therefore, authors were inspired to summarize and discuss nanoparticle formulations for EGFR targeted drug delivery system, related to types of nanoparticle, carrier bases, and its targeting mediators.

\section{Methodology}

This review was obtained from Scopus database by using specific keywords "EGFR, targeted and nanoparticles," by following an inclusions criteria (related to specific keywords) and exclusions criteria (opinions, reviews and unrelated topics). We collected about 27 journals published in 20172019 as a primary literatures, and 36 journals published before 2017 as supporting literature. The flowchart of methodology can be seen in Figure 1.

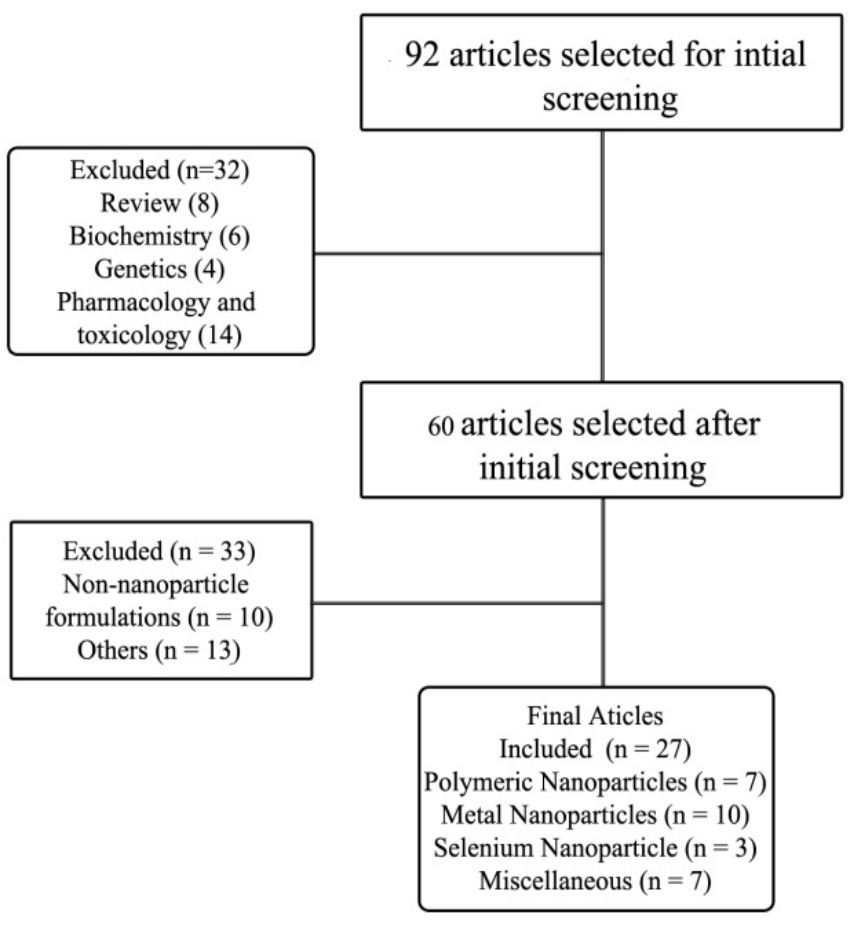

Figure 1. Flowchart of methodology

Table 1. Recent Nanoparticle formulations of EGFR-Targeted drug delivery system

\begin{tabular}{llllll}
\hline \multicolumn{1}{c}{$\begin{array}{c}\text { Types of } \\
\text { nanoparticle }\end{array}$} & \multicolumn{1}{c}{ Name of nanoparticle } & $\begin{array}{c}\text { Main base } \\
\text { nanoparticle }\end{array}$ & Targeting mediator & Targeted cells & Ref. \\
\hline $\begin{array}{l}\text { Polymeric } \\
\text { nanoparticle }\end{array}$ & $\begin{array}{l}\text { siMad2-loaded EGFR } \\
\text { targeted Chitosan } \\
\text { nanoparticles } \\
\text { curcumin-encapsulated and }\end{array}$ & Chitosan and PEG & EGFR peptide & A549 WT \& A549 & [35] \\
$\begin{array}{l}\text { Polymeric } \\
\text { nanoparticle }\end{array}$ & $\begin{array}{l}\text { EGF-conjugated chitosan/ } \\
\text { TPP nanoparticles }\end{array}$ & & EGF & MKN45 and GES & {$[36]$} \\
$\begin{array}{l}\text { Polymeric } \\
\text { nanoparticle }\end{array}$ & $\begin{array}{l}\text { GE11-modified Cur-loaded } \\
\text { PLGA-PEG nanoparticles } \\
\text { (GE11-Cur- }\end{array}$ & PLGA-PEG & GE11 & MCF-7 & [37] \\
& NPs) & & & & \\
\hline
\end{tabular}


Table 1. continue

\begin{tabular}{|c|c|c|c|c|c|}
\hline $\begin{array}{c}\text { Types of } \\
\text { nanoparticle }\end{array}$ & Name of nanoparticle & $\begin{array}{c}\text { Main base } \\
\text { nanoparticle }\end{array}$ & Targeting mediator & Targeted cells & Ref. \\
\hline $\begin{array}{l}\text { Polymeric } \\
\text { nanoparticle }\end{array}$ & $\begin{array}{l}\text { EGFR peptide (GE11) } \\
\text { targeted, pH sensitive, } \\
\text { DTX and CUR prodrug } \\
\text { nanoparticles }\end{array}$ & PLGA-PEG & GE11 & LNCaP cells & [38] \\
\hline $\begin{array}{l}\text { Polymeric } \\
\text { nanoparticle }\end{array}$ & $\begin{array}{l}\text { Mussel-Inspired PLGA/ } \\
\text { polydopamine Core-shell } \\
\text { Nanoparticle }\end{array}$ & $\begin{array}{l}\text { PLGA- } \\
\text { Polydopamine }\end{array}$ & PEG-Cetuximab & UMSCC 22A & [39] \\
\hline $\begin{array}{l}\text { Polymeric } \\
\text { nanoparticle }\end{array}$ & & $\begin{array}{l}\text { poly(glycidyl } \\
\text { methacrylate) } \\
\text { (PGMA) }\end{array}$ & GE11 & $\begin{array}{l}\text { MDA-MB-231 and } \\
\text { MCF-7 }\end{array}$ & [40] \\
\hline $\begin{array}{l}\text { Polymeric } \\
\text { nanoparticle }\end{array}$ & $\begin{array}{l}\text { paclitaxel nanoparticles } \\
\text { co-delivered with } \\
\text { microRNA-7 }\end{array}$ & $\begin{array}{l}\text { monomethoxy } \\
\text { (polyethylene } \\
\text { glycol)-poly } \\
\text { (D,L-lactide-co- } \\
\text { glycolide)-poly } \\
\text { (L-lysine)mPEG- } \\
\text { PLGA-PLL }\end{array}$ & mPEG-PLGA-PLL & $\begin{array}{l}\text { HO8910pm } \\
\text { (Ovarian cancer) }\end{array}$ & [41] \\
\hline $\begin{array}{l}\text { Polymeric } \\
\text { nanoparticle }\end{array}$ & $\begin{array}{l}111 \text { In-labeled polymeric } \\
\text { nanoparticles } \\
\text { incorporating a ruthenium- } \\
\text { based radiosensitizer }\end{array}$ & $\begin{array}{l}\text { Polylactic-co- } \\
\text { glycolic acid } \\
\text { (PLGA) }\end{array}$ & hEGF & $\begin{array}{l}\text { OE21, OE } 33 \text { and } \\
\text { FLO-1 }\end{array}$ & [42] \\
\hline Metal nanoparticle & $\begin{array}{l}\text { nanosecond-laser } \\
\text { irradiation - gold } \\
\text { nanoparticles }\end{array}$ & AuNPs & Cetuximab & OVCAR-3 & [45] \\
\hline Metal nanoparticle & $\begin{array}{l}\text { C-e6 (photosensitizer)-gold } \\
\text { nanoparticle }\end{array}$ & AuNPs & EGF & MDA-MB-468 & {$[46]$} \\
\hline Metal nanoparticle & $\begin{array}{l}\text { VHH-122 and C225 } \\
\text { - EGFR targeted gold } \\
\text { nanoparticle }\end{array}$ & $\begin{array}{l}\text { AuNPs and PEG } \\
\text { lingker }\end{array}$ & $\begin{array}{l}\text { Cetuximab and } \\
\text { single-domain } \\
\text { ilama-derived anti- } \\
\text { EGFR antibody }\end{array}$ & $\begin{array}{l}\mathrm{A} 431 \text { and } \mathrm{C} 57 \mathrm{BL} / 6 \\
\text { mice }\end{array}$ & [47] \\
\hline Metal nanoparticle & $\begin{array}{l}\text { Multifunctional } \\
\text { nanoclusters of } \\
\text { NaYF4:Yb3+,Er3+ } \\
\text { upconversion } \\
\text { nanoparticle and gold } \\
\text { nanorod }\end{array}$ & AuNPS & C-225 & $\begin{array}{l}\text { A549 (EGFR- } \\
\text { positive), HTB9 } \\
\text { and T24T (Human } \\
\text { bladder cancer) }\end{array}$ & {$[48]$} \\
\hline Metal nanoparticle & $\begin{array}{l}2.4 \mathrm{~nm} \text { thiolate-protected } \\
\text { gold } \\
\text { nanoparticles }\end{array}$ & AuNPs & Cetuximab & $\begin{array}{l}\text { U87 MG, } \\
\text { ATCC HTB-14 and } \\
\text { HT-1080, ATCC } \\
\text { CCL-121 }\end{array}$ & [49] \\
\hline Metal nanoparticle & $\begin{array}{l}\text { DOX-loaded Fe3O4@ } \\
\text { polydopamine } \\
\text { multifunctional } \\
\text { nanocomposites }\end{array}$ & $\begin{array}{l}\mathrm{Fe} 3 \mathrm{O} 4- \\
\text { polydopamine }\end{array}$ & EGFR & DLD-1 & {$[50]$} \\
\hline Metal nanoparticle & $\begin{array}{l}\text { lipid-encapsulated targeted } \\
\text { superparamagnetic } \\
\text { iron oxide nanoparticles }\end{array}$ & Iron oxide & $\begin{array}{l}\text { Cetuximab- } \\
\text { iminothiolane }\end{array}$ & $\mathrm{U}-251$ & {$[51]$} \\
\hline Metal nanoparticle & nanoparticles & $\mathrm{Fe} 3 \mathrm{O} 4-\mathrm{Au}$ & Cetuximab (C225) & $\mathrm{U}-251$ & {$[52]$} \\
\hline Metal nanoparticle & $\begin{array}{l}\text { Zinc oxide and aluminium- } \\
\text { doped zinc oxide } \\
\text { nanoparticles }\end{array}$ & $\begin{array}{l}\text { Zinc oxide- } \\
\text { alumnium }\end{array}$ & & A549 and CL1-5 & [53] \\
\hline
\end{tabular}


Table 1. continue

\begin{tabular}{|c|c|c|c|c|c|}
\hline $\begin{array}{c}\text { Types of } \\
\text { nanoparticle }\end{array}$ & Name of nanoparticle & $\begin{array}{c}\text { Main base } \\
\text { nanoparticle }\end{array}$ & Targeting mediator & Targeted cells & Ref. \\
\hline Metal nanoparticle & $\begin{array}{l}\text { Cetuximab-modifedCuS } \\
\text { nanoparticles }\end{array}$ & $\mathrm{CuS}$ & Cetuximab & $4 \mathrm{~T} 1$ cells & [54] \\
\hline $\begin{array}{l}\text { Selenium } \\
\text { nanoparticle }\end{array}$ & $\begin{array}{l}\text { GE11 peptide conjugated } \\
\text { selenium nanoparticles }\end{array}$ & Selenium & GE11 peptide & $\begin{array}{l}\text { KYSE-150 cell line } \\
\text { and EC9706 cell }\end{array}$ & {$[55]$} \\
\hline $\begin{array}{l}\text { Selenium } \\
\text { nanoparticle }\end{array}$ & $\begin{array}{l}\text { Highly uniform selenium } \\
\text { nanoparticle }\end{array}$ & $\begin{array}{l}\text { Selenium- } \\
\text { gadolinium chelate }\end{array}$ & $\begin{array}{l}\text { PAMAM and } \\
\text { DTSSP }\end{array}$ & NPC cells & {$[56]$} \\
\hline $\begin{array}{l}\text { Immuno } \\
\text { nanoparticle }\end{array}$ & $\begin{array}{l}\text { anti-EGFR } \\
\text { immunonanoparticles }\end{array}$ & $\begin{array}{l}\text { DMKE cholesterol, } \\
\text { DSPE, mPEG } \\
2000 \text { and DSPE- } \\
\text { PEG2000-Mal }\end{array}$ & $\begin{array}{l}\text { thiolated anti- } \\
\text { EGFR }\end{array}$ & SK-OV-3 & [57] \\
\hline Liposome & $\begin{array}{l}\text { Smart nanoparticles } \\
\text { assembled by endogenous } \\
\text { molecules }\end{array}$ & DOTAP/DOPE & Hyluronic acid & HCCLM3 & {$[58]$} \\
\hline $\begin{array}{l}\text { Organic } \\
\text { nanoparticle }\end{array}$ & $\begin{array}{l}\text { Fluorescent organic } \\
\text { nanoparticles }\end{array}$ & FON & EGF & MDA-MB-468 & [59] \\
\hline $\begin{array}{l}\text { Unimolecular } \\
\text { nanoparticle }\end{array}$ & $\begin{array}{l}\text { Tumour-targeted } \mathrm{pH} / \mathrm{redox} \\
\text { dual-sensitive unimolecular } \\
\text { nanoparticles }\end{array}$ & $\begin{array}{l}\text { H40-cationic } \\
\text { segment-PEG }\end{array}$ & GE11 & MDA-MB-468 & {$[60]$} \\
\hline $\begin{array}{l}\text { Biomimetic } \\
\text { nanoparticle }\end{array}$ & $\begin{array}{l}\text { Anti-EGFR-iRGD } \\
\text { recombinant protein } \\
\text { modifed } \\
\text { biomimetic nanoparticles }\end{array}$ & RBCm-PLGA & $\begin{array}{l}\text { Palmitate-anti- } \\
\text { EGFR-iRGD }\end{array}$ & $\begin{array}{l}\left(\text { ATCC } ® \text { HTB } 37^{\mathrm{TM}}\right) \text {, } \\
\text { HT-29 } \\
\left(\text { ATCC } ® H T B-38^{\mathrm{TM}}\right) \text {, } \\
\text { and SW480 } \\
\left(\text { ATCC } ® C C L 228^{\mathrm{TM}}\right)\end{array}$ & [61] \\
\hline $\begin{array}{l}\text { self-assembled } \\
\text { lipid nanoparticles }\end{array}$ & $\begin{array}{l}\text { Paclitaxel-loadedself- } \\
\text { assembled lipid } \\
\text { nanoparticles }\end{array}$ & $\begin{array}{l}\text { MO, DSPE-PEG- } \\
\text { Mal }\end{array}$ & Pluronic F127 & HX-62 & {$[62]$} \\
\hline $\begin{array}{l}\text { lipoplex } \\
\text { nanoparticle }\end{array}$ & $\begin{array}{l}\text { tethered cationic lipoplex } \\
\text { nanoparticle (TCLN) }\end{array}$ & lipoplex & MBs & NSCLC & {$[63]$} \\
\hline
\end{tabular}

\section{Discussion}

\subsection{Nanoparticles drug delivery system}

In recent years, nanomedicine becomes an essential role in clinical therapy. Multifunctional capabilities of nanoparticles provide a water solubility improvement and increase dissolution rate, as a function of its nano-size which inversely proportional with a large of surface area. The surface area is directly proportional to the contact area of particles with solvent, this mechanism is responsible and affected in solubility and dissolution rate [29]. Moreover, nanomedicine in clinical application refers to highly specific at the intermolecular level for curing diseases or repairing damaged tissues, such as nerve, muscle, or bone. Liposomes, dendrimers, solid lipids nanoparticles, polymeric nanoparticle, and magnetic nanoparticles are examples of nanocarriers that have been formulated as drug delivery systems [30].

Nanoparticle drug delivery system is a sophisticated modification technique to resolve the limitations of drugs, such as a poor solubility in water and a site selectivity problem of anticancer drugs[31]. Nanoparticles formulation commonly used as targeted drug delivery carrier to particular receptors, genes and extra or inter-cellular molecule, which are have been formulated in several types of nanoparticle, for example nano polymeric, dendrimer, solid lipid nanoparticles, metal nanoparticles and liposomes. Selection of the suitable excipients plays a crucial role in nanoparticles formulation for drug delivery of active drug substances to the specific target. Mannose, hyaluronic acid, GE11 peptide, folic acid, epidermal growth factor (EGF) and monoclonal antibody cetuximab are the primary targeting mediators to deliver active pharmaceutical ingredient by their high-affinity properties with receptors on the surface cells membrane, specific gene or by others mechanism of actions. Furthermore, 
nanoparticle formulation also can enhance the penetration rate, membrane transport, cellular uptake and bio adhesive interaction with the cells membrane [32-33]. In line with the enhancement of solubility, dissolution and absorption rate of drugs, nanoparticle formulation improves bioavailability of drugs in systemic circulation [34].

\section{2. $E G F R$}

EGFR/HER1, one of the human epidermal receptors (HER1, HER2, HER3 and HER4), includes in the receptor tyrosine kinases (RTK) family. EGFR/HER1 consists of a single chain transmembrane of glycoprotein, an extracellular ligand-binding domain, a transmembrane region, and an intercellular tyrosine kinase domain [1-2]. The EGFR has ability in cell regulations, such as proliferation, growth factor, cell differentiation, and apoptosis. Moreover, EGFR plays a crucial role in progression of the cancer cells, cells formation, metastasis, and angiogenesis [3-5]. Furthermore, the EGFR becomes a specific characteristic of several cancer cells, which is marked by EGFR overexpressed on surface cells membrane known as EGFR-positive cells. Therefore, many studies of the cancer cells treatment using the EGFR as the primary target for anti-cancer drug delivery improved the efficacy by increasing the selectivity and reducing the side effects on healthy cells. In previous studies, EGFR targeted drug delivery system was prepared by many approaches, including anti-cancer drugs combination therapy with targeting mediators and complex formulation mediated by nanoparticle-targeted drug delivery system [17-19].

\subsection{Nanoparticles formulation as an EGFR- targeted drug delivery system}

In the last decade, EGFR-targeted nanoparticles become a promising modification which could provide an excellent action of many anti cancer drugs with high selectivity property against cancer cells and has low toxicity effect on healty cell. The development of EGFR-targeted drug delivery systems have been formulated in several types of nanoparticles system where consist of specific agents which are correspondent to deliver the nanoparticle onto EGFR-positive cells. In the past three years, most of nanoaparticles formulation are made in nanoparticle targeted drug delivery system include specific targeted on EGFR. A complex mechanism of actions on those system become an impressive thing to learn. Therefore, in this study we inspired summarize and try to compare of these nanoparticle formulation (Table 1.)

\subsubsection{Polymeric based nanoparticle for EGFR- targeted drug delivery system}

Polymeric based nanoparticle is commonly used as drug delivery system which has biodegradable and non-toxic properties. The polymers provide modified release and targeted drug delivery system into specific target cells by a different mechanism of action such as interacted with cells membrane or binding with a particular receptor. Therefore, in this section we summarized the polymeric nanoparticle formulation as a targeted drug delivery system via epidermal growth factor receptor.

Nascimento et al., (2016) developed polymeric nanoparticle using polymers chitosan-PEG as a base of nanoparticle and conjugated with EGFR peptide as a mediator to deliver mad2 siRNA in cisplatinresistance non-small cell lung cancer (NSCLC). The nanoparticle was prepared by self-assembly method and obtained range of nanoparticle size was $(100-230 \mathrm{~nm}),(>+20 \mathrm{mV})$ zeta potentials with the high encapsulation efficiency $(>90 \%)$ ). About $20 \%$ of Mad 2 mRNA level was decreased at $48 \mathrm{~h}$ after treatment compared to control, more over the $\operatorname{Mad} 2$ protein level was reduced to $35 \%$ and $22 \%$ in A594WT and A549DDP cells, respectively. In bio distribution assay, showed that the targeted nanoparticle system has tumour exposure than that of the non-targeted nanoparticle system [35].

Using a similar carrier system, chitosan polymeric nanoparticle was formulated by Tsai et $a l$., for curcumin delivery to specific target. The nanoparticles were obtained with range particle size of $(220-255 \mathrm{~nm})$, PDI $(<0.5)$ and $(>+15 \mathrm{mV})$ zeta potential. In vitro viability cell assay proved that curcumin-encapsulated folate-conjugated chitosan/ TPP nanoparticles (CENP) had better efficiency than curcumin-encapsulated chitosan/TPP nanoparticles (CNP) with $\mathrm{IC}_{50} 3.4 \mu \mathrm{M}$ and $12.8 \mu \mathrm{M}$ in MKN45 and gastric epithelial mucosa (non-cancer) cell line (GES) cells respectively. Localization and cellular 
uptake studies of CENP indicated that curcumin was entered in MKN45 and low permeate in GES cells, interestingly the result showed that CENP has higher two-fold than CNP. On the analysis of radical oxygen species (ROS) and ${ }^{1} \mathrm{O}_{2}$ production in photodynamic therapy (PDT) was indicated that it was more useful for targets the cancers cells, and has more efficient in ROS generation compare to curcumin-encapsulated EGF-conjugated chitosan/ TPP nanoparticles CFNP (comparator) [36].

In another study, Jin et al. created a polymeric nanoparticle as an EGFR targeted drug delivery system for curcumin using (PLGA)-poly(ethylene glycol as the main base polymer with GE11 peptide as a targeting mediator. The nanoparticle was fabricated by emulsification and evaporation method. About $210 \pm 54 \mathrm{~nm}$ of the mean particle size, $-22 \pm 3.6 \mathrm{mV}$ zeta potential and $92.3 \pm 2.7 \%$ entrapment efficiency were obtained. Curcumin, can be released steadily for approximately within 24 hours. Moreover, this system delivered the curcumin onto MCF-7 cells for about 3-fold more than curcumin free. Apoptosis study showed that the proportion of apoptosis cells was (18.9\%) compared to free curcumin $(11 / 0 \%)$. Based on protecting the impact of delivering curcumin in nanoparticle system to xenograft analysis suggested that the nanoparticle system provided the extended period of time over, which is the remains of curcumin in the circulation without stimulating of inflammation response and enhanced the delivery of the curcumin to xenograft tumours [37].

Other polymeric nanoparticle formulation for curcumin compound was carried out by Yan et al. Docetaxel was combined with the curcumin as a drugs payload against prostate cancer. It was fabricated by the solvent displacement method. The nanoparticle has a mean particle size of $167 \mathrm{~nm}$, $-37.5 \mathrm{mV}$ zeta potential with entrapment efficiency $91.4 \pm 4.2$ and $87.5 \pm 3.9 \%$ for docetaxel and curcumin respectively. In targeted drug delivery evaluation, cellular uptake study showed that the nanoparticle system has a cellular uptake efficiency and significantly higher than that of control, with percent efficiency was $80 \%$ at 12 hours posttreatment, with the $\mathrm{IC}_{50}$ value were $0.058 \pm 0.008 \mu \mathrm{M}$ and $0.58 \pm 0.06 \mu \mathrm{M}$ for nanoparticle targeted containing docetaxel and curcumin, respectively. In addition the nanoparticle system has stronger antitumour efficacy than other control groups treatment confirmed by in-vivo evaluation [38].

In 2017, He et al., performed a polymeric nanoparticle for doxorubicin using poly lacticco-glycolic acid (PLGA) copolymer loaded polydopamine (PD)as a correspondent for photo thermal therapy. On the nanoparticle surface was decorated by PEG and cetuximab anti-EGFR monoclonal antibody as a targeting agent for EGFR. In this formulation, about $142 \mathrm{~nm}$ of nanoparticle size with $-14.5 \pm 0.5 \mathrm{mV}$ of zeta potential was observed. The nanoparticle has an excellent photo thermal converting property, with the efficiency $16.9 \%$. Which on live and dead cell assay showed that NIR irradiation-induced photo thermal effect can kill the cancer cells while PLGA/PD nanoparticle its self non-toxic. On cellular uptake study demonstrated that the uptake on EGFR-positive cell (UMSCC 22A) selectively enhanced compared to EGFRnegative cell [39].

In other study, formulation of polymeric nanoparticle was performed by Tristan et al., in 2018, they gave a perspective about the distinction of active and passive targeting cancer cells in nanoparticle drug delivery system. Herein, docetaxel as a drug payload was prepared with (glycidyl methacrylate) (PGMA) as a base polymer and conjugated with GE11 peptide as a targeting agent to epidermal growth factor receptor. The nanoparticle was formulated by oilin-water emulsion method. the formula has a mean particle size of $195.3 \mathrm{~nm}, 0.104$ polydispersity index, $24.2 \pm 5.8 \mathrm{mV}$ zeta potential with percent drug content of $24.0 \pm 1.3 \% \mathrm{w} / \mathrm{w}$. Drug release study showed a $57.1 \%$ released over six days. In cellular uptake study described the nanoparticle system associated significantly less than lysosomes compared to non-EGFR targeted. On therapeutic efficacy assay, the $\mathrm{IC}_{50}$ of nanoparticle system was $5.1 \mathrm{ng} / \mathrm{mL}$ and $173.5 \mathrm{ng} / \mathrm{mL}$ in MDA-MB-231 and MCF-7 cells respectively, whereas for nonEGFR targeted was $30.1 \mathrm{ng} / \mathrm{mL}$ and $886.2 \mathrm{ng} / \mathrm{mL}$ in MDA-MB-231 and MCF-7 cells respectively. These results were thereby indicating that the EGFR targeted nanoparticle has high cytotoxicity compare to non-EGFR targeted [40].

Other polymeric nanoparticle formulation 
was conducted by Cui et al. for increasing the chemotherapeutic efficacy of paclitaxel with MicroRNA-7 (miR-7). Here, monomethoxy (polyethylene glycol)-poly (D,L-lactide-coglycolide)-poly(L-lysine) triblock copolymer (mPEG-PLGA-PLL) are used as a main base carrier. This study resulted the mean particle size of $105.0 \pm 0.86 \mathrm{~nm}, 19 \pm 2.04 \mathrm{mV}$ zeta potential, PDI $0.276 \pm 0.007$ with high entrapment efficiency of paclitaxel and miR-7 was $84.1 \pm 1.31 \%$ and $98.3 \pm 0.21 \%$ respectively. A controlled release system profile of paclitaxel approximately $80 \%$ within 24 hours, whereas the miR-7 has a slowrelease profile of $20 \%$ within 24 hours. The nanoparticle system significantly up regulated the miR-7 relatively gene expression up to 15 -fold and $>40$-fold in the HO8910pm cells at the miRNA dose of $100 \mathrm{nM}$ in 24 and 48 hours. In addition the cytotoxic study was thereby indicated that the nanoparticle system has high cytotoxic level more than control, with $\mathrm{IC}_{50}$ values of $2.85 \pm 0.45$ and $0.41 \pm 0.03$ in 48 and 72 hours, respectively. An alteration of pathways indicated that nanoparticle system could partially inhibit the activation of the EGFR/ERK pathway, in addition its data suggest the nanoparticle system has a sensitive property onto cells via EGFR/ERK pathways, and based on apoptosis study showed that the nanoparticle system had an apoptosis rate of $70 \%$ in HO8910 cells. These partially distributed on nanoparticle system around the nucleus of tumour cells and observed by biodistribution assay. miRNA targets in ovarian tumours of paclitaxel/miR-7 in nanoparticle system showed a high increase about 21-fold compared to control [41].

Gill et al., performed study about nanoparticle lebelled ${ }^{111}$ In and incorporating a ruthenium-based DNA replication inhibitor with $\mathrm{Ru}$ (phen)2(tpphz)2+ (phen $=1,10$-phenanthroline, $\operatorname{tpphz}=$ tetra pyridophenazine) $\mathrm{Ru} 1$ as a radio sensitizer for EGFR targeted drug delivery system. On this nanoparticle system, polylactic-co-glycolic acid used as a base carrier which is conjugated with diethylene triamine penta acetic acid-human epidermal growth factor DTPA-hEGF. This formulation was prepared by a double emulsion evaporation method. The nanoparticle has a mean particle size was $133.0 \mathrm{~nm}$, $-4.7 \mathrm{mV}$ zeta potential and 0.236 of polydispersity index. About $>80 \%$ of uptake was blocked for a high concentration of hEGF employed. Besides, the results consistent with EGFR binding and EGFR-mediated the cellular uptake of nanoparticle system. In subcellular distribution assay showed a higher level was observed $(14.8 \pm 3.8 \%)$ for nanoparticle system in both of cells (OE21 and OE33) compare with non-containing DTPA in nanoparticle system. Rul uptake and localization indicated that the majority was $(>65 \%)$ in cells after 24 hours treatment. The nanoparticle system with Rul had the most excellent cytotoxicity on EGFR overexpressing OE21 cells compared with non-targeted nanoparticle. Also, the nanoparticle system with radiolabeled ${ }^{111}$ In induced a substantial decrease in clonogenic survival (relative to untreated). In bio distribution assay showed a prominent result for uptake of radioactivity into the liver, spleen and kidneys with represent of tumour uptake was $0.6-1 \%$ of total injected dose/g with a tumour muscle ratio range of $2.5-4$, in this assay deduce, there was no significant different between tumour-associated radioactivity or tumour muscle ratio between OE21 cell and FLO-1 xenograft models [42].

\subsubsection{Metal-based nanoparticle for EGFR-targeted drug delivery system}

Nowadays, metal-based nanoparticles are types of drug delivery system which commonly used in nanomedicine for disease treatment. A number of metals have a potential therapy against cancer cells. Metals also have some special physicochemical characteristic as supporting mechanism of action, including magnetic, thermal and photosensitive properties of metals. These are can be modified, developed, and could be an approach to achieve a better performance. In this section we would like to emphasize about metals functionalized in nanomedicine especially by nanoparticle drug delivery system [43-44].

\subsubsection{Gold based nanoparticle}

Yao et al. developed a metal nanoparticle using gold as a main metal in nanoparticle system. This formulation aimed to increase a cell membrane permeability induced by pulsed-laser irradiation for targeted molecule delivery which 
is for EGFR targeted drug delivery system onto ovarian carcinoma cell line OVCAR-3. The EGFR targeted was mediated by conjugation of antibody cetuximab as a targeting mediator. An overall results assay proved that the metal nanoparticle system could be excellently targeted on EGFR. In addition, permeability was successfully induced by laser irradiation, about $150 \mathrm{kDa}$ of dextran was delivered into cancer cells with an efficiency of $70 \%$. The perforation efficiency was sensitive with an incubation time of cells conjugate, whereas for the perforation rate was highly affected by cells during irradiation process, as bright as the high of perforation efficiency will be achieved with lower irradiation or by a lower concentration of nanoparticle [45].

The instability property of several biomolecules becomes a challenge during manufacturing process. EGF is one of ligand which is could be easily degraded by environmental intervention. To deeply understand about those mechanisms, Bhattacharjee et al. performed a gold nanoparticle formulation, and studied the changes of secondary structure of epidermal growth factor. The study was aimed to investigate the change of secondary structure in the protein of EGFR, which can be a fundamental consideration for modifying synthesis procedure and could be a multifunctional approach to achieve an optimum result. To provide an overexpressed EGFR, it was performed on breast cancer cells, which are known as an EGFR-positive cell. This study resulted the $\beta$-sheet and loop structure in EGF protein were increased by steeps synthesis but will be decreased when the protein bind with its receptor [46].

In 2018, development of gold nanoparticle also was formulated by Ashton et al,. The study focussed on developing of EGFR targeting on lung adenocarcinoma cell (A431), herein the nanoparticles system was conjugated with the antiEGFR antibody cetuximab and with the anti-EGFR derived as a targeting mediators. In vitro and in vivo study using C57BL/6 mice and nude mice with A431 subcutaneous tumours were observed. Results showed that the nanoparticle system conjugated with cetuximab had a shorter blood residence time than non-targeted and other nanoparticle systems. Overall results proved a targeted drug delivery onto EGFR and demonstrated a contrast agent nanoparticle system could be a compromising as a detector tumour receptor overexpression [47].

Cho et al. formulated a multifunctional nanocluster of $\mathrm{NaYF}_{4}: \mathrm{Yb}^{3+}, \mathrm{Er}^{3+}$ up conversion nanoparticle with gold nanorod by PEGylation then conjugated with C-225 antibody as a targeting mediator for delivery onto EGFR in the bladder cancer cell. A nanocluster was $11 \mathrm{~nm}$ width, length of $43 \mathrm{~nm}$, and localized surface plasmonear $800 \mathrm{~nm}$. Results demonstrated that the targeting mediator C-225 antibody could bind with EGFR within 2 hours of incubation. Based on upconversion photoluminescence imaging, obtained high-contrast images showed that the nanoparticle system selectively binding with EGFR-positive cells, and there is no bind interaction with EGFRnegative cells [48].

Another gold nanoparticle formulation was performed by Groysbeck et al.. Au monolayered was used as the main base nanoparticle where obtained by mixed thionitro benzoid acid-, thiamine benzoid acid. Herein the nanoparticle was made as an EGFR-targeted drug delivery system using EGFR antibody cetuximab as a targeting mediator. The selective-binding property was appeared when the nanoparticle system added to EGFR-positive glioblastoma cells, which were overexpressed the EGFR on surface cells membrane, it also showed the inhibition effect of EGFR autophosphorylation and entered into endosomes like Cetuximab. Overall, thereby indicated that the nanoparticle system could be an approach techniques to provide the selective target delivery [49].

\subsubsection{2 $\mathrm{Fe}_{3} \mathrm{O}_{4}$ based nanoparticle}

$\mathrm{Fe}_{3} \mathrm{O}_{4}$ based nanoparticle was performed by $\mathrm{Mu}$ et al. In this study, nanoparticles system were made by $\mathrm{Fe}$ as a main based nanoparticle for doxorubicin targeted drug delivery system on EGFR-positive cells (DLD-1 colorectal adenocarcinoma), for magnetic resonance imaging and antitumour chemo-photothermal therapy. EGFR antibody direct polydopamine was coated on nanoparticle surface, which is responsible as a targeting mediator to achieve an EGFR-targeted delivery system. This system revealed a high storage capacity of drug and also has high photo thermal conversion 
efficiency. The nanoparticles system without doxorubicin had no cytotoxic effect, however for the nanoparticle system containing doxorubicin was significant can decrease cell viability $(\sim 5 \%$ of remaining cell viability) caused of doxorubicin release triggered by of both ablation photothermal and near-infrared light when the nanoparticles were an uptake in DLD-1 cells. In conclusion, this study demonstrated that the nanoparticles system become a multifunctional approach and potential to enhance the effectiveness of combined the cancer chemo-photo thermal therapy via EGRF targeted drug delivery system [50].

Another study of $\mathrm{Fe}$ nanoparticle was performed by Chen et al., which aimed for identification of the EGFR-positive glioblastoma cells, which was the lipid encapsulated targeted super paramagnetic iron oxide nanoparticles (SPIO)became a tool to provide this mechanism through anti-EGFR cetuximab conjugated (EGFR-SPIO). The results showed that the system preferentially targeted onto U-251 cells, and based on T2 MR image assay demonstrated that the T2 relaxation time of nanoparticles system was successful to identifying the EGFR-positive cells of human glioblastoma cell lines include U-87 MG which have a low EGFR expression compared to other cells [51].

$\mathrm{Lu}$ et al. formulated composite magnetic nanoparticles consisted both of two types metals. $\mathrm{Fe} O \mathrm{O} @ \mathrm{Au}-\mathrm{C} 225$ composite-targeted MNPs (Cetuximab (C225)-encapsulated coreshell Fe3O4@Au magnetic nanoparticles) as a delivery agent of magneto photothermal therapy onto specific EGRF on glioma cells. Based on inhibitory and apoptosis study showed that the nanoparticle system combined (MFH+NIR) had a strong inhibitory effect and apoptosis rate than other group treatment, in addition by the marker of up-regulation overexpression of caspase-3,8,9 indicated that was an excellent antitumour effect. In vivo study showed that the nanoparticles system are significant can exhibit tumour growth suppression better than other groups. In conclusion, this study demonstrated that the nanoparticles system have great potential as a nanoplatform in clinical treatment for human glioma disease [52].

\subsubsection{ZnO-Aluminium and $\mathrm{Cu}$ based nanoparticle}

Formulation of EGFR targeted nanoparticles have been conducted with several types of metal atoms or compounds as the core system includes $\mathrm{ZnO}, \mathrm{Al}$ and $\mathrm{Cu}$. In 2017 Bai et al. developed a zinc oxide-aluminium as a base for their nanoparticles formula which was aimed to achieve an EGFRmutated targeted cells (CLI-5) and wild-type EGFR (A549) human lung adenocarcinoma cells. The results found that a significantly reduced the cells cancer viability after 18 and 24 hour exposure on both cell lines. In colony formation analysis resulted that the A549 cells were re-grew with 20 $\mu \mathrm{g} / \mathrm{mL}$ Al-ZnONP20 post-treatment, in this study also proved that the nanoparticles formula could inhibit the activating conversion of light chain 3 (LC3) levels in EGFR mutated cells (CLI-5), whereas activated in A549 cells line. Herein, can be deduce that both of nanoparticles system are selective sensitive with EGFR-mutated of human lung adenocarcinoma cells [53].

Another metal nanoparticle formulation was performed by Li et al. The nanoparticles system was consist of $\mathrm{CuS}$ as main based nanoparticles and modified with cetuximab as a targeting mediator to provide the drug delivery targeted onto specific EGFR receptor. It was also integrating with nearinfrared-II-responsive photothermal therapy and anti-vessel treatment. The result showed that the nanoparticles system were comparable accumulation confirmed by cellular uptake study, biodistribution assay, and immunohistochemistry staining demonstrated that the nanoparticles system was impressive can inhibit the formation of tumour formation and progression of tumour vessel. In conclusion, this study suggested that the nanoparticles system becomes a delivery carrier for the anti-cancer drug for utilized in clinical treatment for the cancer diseases, and the safety properties of this system can be applicable with no side effect [54].

\subsubsection{Selenium-based nanoparticle}

Another types of nanoparticle formulation are namely selenium nanoparticles. It was formulated by $\mathrm{Pi}$ et al. In this formulation, GE11 peptide (targeting mediator) was conjugated in selenium nanoparticles to provide EGFR targeted for oridonin 
delivery. The nanoparticle system (GE11-Ori-Se NPs) improved the cellular uptake in cancer cells, strong inhibit the growth of cancer cells and reduce the toxicity effect in healthy cells. On apoptosis study the nanoparticles system showed can induce the programmed cells death by producing reactive oxygen species, activating the mitochondriadependent pathway, inhibiting EGFR-mediated PI3K/AKT and inhibiting Ras/Raf/MEK/ERK pathways. Also, the nanoparticle system had an active targeting effect against esophageal cancer bearing mice. In a nude mice xenograft model, the nanoparticles system were significant inhibited the tumour growth of tumour angiogenesis by reducing the CD31 (angiogenesis-marker), enhancing the IL-2 and improving TNFa production [55].

In 2019, Huang et al. also performed a seleniumbased nanoparticle for EGFR targeting using a different cells target with the previous study. It also contained several agents such as (EGFR) as targeting molecule, gadolinium chelate responsible for magnetic resonance imaging contrast agent, polyamidopamine (PAMAM), 3,3'-dithiobis (sulfosuccinimidyl propionate) (DTSSP) as agents were responsible for intratumoural glutathione and $\mathrm{pH}$, and using 5-fluorouracil (5Fu) and cetuximab as a drug payload for nasopharyngeal carcinoma (NPC). The result of in vitro cellular study showed the excellent capability as a magnetic resonance imaging with not only can increase the intracellular uptake, but also increase the penetration rate, inhibit the cells growth, invasion and migration of tumour cells. In addition, the bio responsive property of the nanoparticle system in the tumour microenvironment effectively improved the delivery targeted and anticancer efficiency [56].

\subsubsection{Miscellaneous based nanoparticle for EGFR- targeted drug delivery system}

Kim et al. developed an anti-EGFR immune nanoparticles as targeted drug delivery carrier into the specific tumour for therapeutic siRNAs. The immune nanoparticles were conjugated with the four types of EGFR antibody named (immunolipoplexes, immunoviroplexes, immunoliposomes and immunovirosomes). In this study, immunoviroplexes was the most efficient for siRNA transfection into cells target. Therefore,
Janus kinase-3 and vimentin siRNAs were filled into immunoviroplexes and immunolipoplexes, then evaluated in SK-OV-3 tumour xenografts of mice. The results showed that the both nanoparticle system efficiently delivered the siRNAs to the tumour tissues and significantly inhibited the tumour growth. Also, administration of doxorubicin-loaded anti-EGFR immunoviroplexes showed that an impressive result and synergistic with the tumour growth inhibition. Overall, an efficient siRNA delivery targeted was achieved and combination of chemotherapy drugs with RNAi therapy could be a necessary consideration as a plausible modality for cancer treatments with the most efficient than other conventional therapy of cancer diseases [57].

Liang et al. designed the smart nanoparticles assembled by endogenous an molecule that was formulated as a delivery carrier for siRNA and anticancer therapy for targeting in CD44 and EGFR named (HLPR). HPLR was consist of siRNA in the core of nanoparticles and surrounded by a lipid bilayer. While on the surface it was conjugated with thin hyaluronic acid and amino acid sequences of YHWYGYTPQNVI as a mediator targeted for both CD44 and EGFR. Due to its stability in systemic circulation and ability to reach the target tissue through active and passive targeting, the nanoparticle system might be entered into tumour cells, which is mostly through by EGFR-mediated pathway. After that, hyaluronic acid separated from nanoparticle complex. This hyaluronic aciduncoated then discharged from endosome via DOPE, which could perform membrane fusion, and released peptide/siRNA and siRNA into cytoplasm. Thus it could be assumed that HPLR inhibition was significant into implanted subcutaneous liver tumours growth with absence of toxicity for healthy cells [58].

A bio conjugates fluorescent organic nanoparticle (FONS) was performed by Fauconet al. in 2017. An active targeting property was proved by conjugated FONS with the EGF ligand in EGFR-positive cells. Super-resolution fluorescence microscopy analysis in MDA-MB-468 cells membrane showed the strong asymmetric clustering of conjugated FONs with EGF. This phenomenon could be explained by the multivalency of EGF which could recruit 4.7 EGF/FON and affected high recruitment of the 
nanoparticle and targeting mediator, thus enabled EGFR activation and subsequent phosphorylation efficiently. In conclusion, this study was successfully conjugated EGF, a small protein, to ultra-bright fluorescent nanoparticles [59].

Chen et al. formulated unimolecular nanoparticles for siRNA-targeted drug delivery system by $\mathrm{pH} /$ redox dual-sensitive materials. Based on in vitro studies, the optimal condition to obtain the most rapid release of siRNA from the nanoparticle system was at $\mathrm{pH}=5.3$ and 10 $\mathrm{mM}$ GSH. Hence, using $\mathrm{pH} / \mathrm{redox}$ dual sensitive materials in unimolecular nanoparticles could be promising siRNA delivery system in EGFRpositive cancer cells [60].

Zhang et al. formulated a biomimetic nanoparticle of gambogic acid-loaded into AntiEGFR-iRGD recombinant protein (RBCm-NPs) as a targeting mediator to provide an EGFRtargeting and enhance the antitumour activity in colorectal cancer treatment. It consisted of singledomain antibody (sdAb) of EGFR and tumours penetrating peptide (internalizing RGD peptide), the responsible of bispecific affinity of nanoparticle. This nanoparticle system showed promising activity in the treatment of colorectal cancer due to its targeting ability improvement based in vitro and by in vivo evaluation. Also, the nanoparticles system would not affect the long-term inhibition and short-term cell apoptosis [61].

Zhai et al. designed self-assembled lipid nanoparticles as a carrier for Paclitaxel with active targeting property mediated by an anti-EGFR as targeting mediator in nanoparticle targeted drug delivery system for aggressive ovarian cancer cells. Moreover, a lipid-PEG and Pluronic (F127) were used as stabilizer in this formulation. Compared to in vitro activity of free paclitaxel in HEY an ovarian cancer line, nanoparticle system was exhibited stronger cytotoxic effect. Impressively, both of the EGFR-targeted nanoparticles and nonEGFR-targeted nanoparticles could reduce up to half of the tumour burden in ovarian cancer mouse xenograft model and extend the survival of cells compared to free paclitaxel-treated group. Overall, this study suggested that nanoparticles system have capability as carriers for chemotherapeutics agent such as paclitaxel [62].
Another approach was carried out by Zhou et al. in 2018. They tried to establish the plasminogen activator urokinase receptor(PLAUR)andresistance of gefetinib relationship. PLAUR mRNA in plasma exosomes was detected using a tethered cationic lipoplex nanoparticle (TCLN). The study showed that the PLAUR mRNA in gefitinib-resistance was higher than in gefitinib-sensitive NSCLC patient. This phenomenon was also observed in PC9R and PC9 cells. Zhou et al also found that in PC9R cells EGFR was overexpressed and when it was performed to knockdown, the number of cell apoptosis markedly increased. Through this study, a novel target for gefitinib-resistant NSCLC patients was found, i.e PLAUR [63].

\section{Conclusion}

EGFR overexpression is a specific characteristic of several cancer cells due to its essential role in cancer cells regulation. Therefore, EGFR becomes primary target in cancer diseases treatment. Nanoparticles EGFR-targeted nanoparticles drug delivery system is one of the most successful efforts to mediate this targeted therapy. Nanoparticles systems such as nano-polymeric, nanometal, and biomimetic nanoparticles showed the impressive results on cancer study i.e. increased in cytotoxicity effect, well distributed on a specific target and reduced in side effect to healthy cells. The underlying mechanism of targeted drug delivery system is the result of conjugation of targeting mediators which has high-affinity to the particular receptor with nanoparticles complex. Nanoparticle EGFR-targeted drug delivery system could be a promising anti-cancer drugs carrier on clinical treatments of cancer diseases in the future with the higher effectiveness and lower side effects.

\section{Acknowledgement}

Authors would like to thanks to Fundamental Research Grant (Penelitian Dasar) 2019 no 1373b/ UN6.O/LT/2019, Ministry of Research and Higher Education, Republic of Indonesia that funding of this study.

\section{References}

[1] Yarden, Y. \& Sliwkowski, M. X. Untangling the ErbB signalling network. Nat. Rev. Mol. 
cell Biol.2, 127 (2001).

[2] Kondo, I. \& Shimizu, N. Mapping of the human gene for epidermal growth factor receptor (EGFR) on the $\mathrm{p} 13 \rightarrow \mathrm{q} 22$ region of chromosome 7. Cytogenet. Genome Res.35, 9-14 (1983).

[3] Suzuki, S. et al. Protein overexpression and gene amplification of epidermal growth factor receptor in nonsmall cell lung carcinomas: an immunohistochemical and fluorescence in situ hybridization study. Cancer Interdiscip. Int. J. Am. Cancer Soc.103, 1265-1273 (2005).

[4] Eberhard, A. et al. Heterogeneity of angiogenesis and blood vessel maturation in human tumours: implications for antiangiogenic tumour therapies. Cancer Res.60, 1388-1393 (2000).

[5] Cataldo, V. D., Gibbons, D. L., Pérez-Soler, R. \& Quintás-Cardama, A. Treatment of non-small-cell lung cancer with erlotinib or gefitinib. N. Engl. J. Med.364, 947-955 (2011).

[6] Wang, J. et al. Clinical outcomes of EGFR kinase domain duplication to targeted therapies in NSCLC. Int. J. cancer144, 26772682 (2019).

[7] Burley, T. A. et al. Affibody-based PET imaging to guide EGFR-targeted cancer therapy in head and neck squamous cell cancer models. J. Nucl. Med.60, 353-361 (2019).

[8] Ye, M. et al. Oxidized Vitamin C (DHA) Overcomes Resistance to EGFR-targeted Therapy of Lung Cancer through Disturbing Energy Homeostasis. J. Cancer10, 757 (2019).

[9] Weng, W., Leung, W., Pang, Y. J., Kuo, L. \& Hsu, H. EPA significantly improves anti-EGFR targeted therapy by regulating miR-378 expression in colorectal cancer. Oncol. Lett.16, 6188-6194 (2018).

[10] Dietel, E., Brobeil, A., Tag, C., Gattenloehner, S. \& Wimmer, M. Effectiveness of EGFR/ HER2-targeted drugs is influenced by the downstream interaction shifts of PTPIP51 in HER2-amplified breast cancer cells. Oncogenesis 7, 64 (2018).

[11] Baker, L. C. J. et al. Evaluating imaging biomarkers of acquired resistance to targeted
EGFR therapy in xenograft models of human head and neck squamous cell carcinoma. Front. Oncol.8, 271 (2018).

[12] Peng, H. et al. Anti-EGFR targeted therapy delivered before versus during radiotherapy in locoregionally advanced nasopharyngeal carcinoma: a big-data, intelligence platformbased analysis. BMC Cancer 18, 323 (2018).

[13] Railkar, R. et al. Epidermal growth factor receptor (EGFR)-targeted photoimmunotherapy (PIT) for the treatment of EGFR-expressing bladder cancer. Mol. Cancer Ther.16, 2201-2214 (2017).

[14] Hou, H. et al. Targeted next generation sequencing in Chinese colorectal cancer patients guided anti-EGFR treatment and facilitated precision cancer medicine. Oncotarget8, 105072 (2017).

[15] Gajadhar, A. S., Bogdanovic, E., Muñoz, D. M. \& Guha, A. In situ analysis of mutant EGFRs prevalent in glioblastoma multiforme reveals aberrant dimerization, activation, and differential response to anti-EGFR targeted therapy. Mol. Cancer Res.10, 428-440 (2012).

[16] Gottschalk, N., Kimmig, R., Lang, S., Singh, M. \& Brandau, S. Anti-epidermal growth factor receptor (EGFR) antibodies overcome resistance of ovarian cancer cells to targeted therapy and natural cytotoxicity. Int. J. Mol. Sci.13, 12000-12016 (2012).

[17] Ninomiya, T. et al. Phase 2 Study of Afatinib Alone or Combined With Bevacizumab in Chemonaive Patients With Advanced NonSmall-Cell Lung Cancer Harboring EGFR Mutations: AfaBev-CS Study Protocol. Clin. Lung Cancer 20, 134-138 (2019).

[18] Colzani, B. etal. Design of smart GE11-PLGA/ PEG-PLGA blend nanoparticulate platforms for parenteral administration of hydrophilic macromolecular drugs: synthesis, preparation and in vitro/ex vivo characterization. Int. J. Pharm.511, 1112-1123 (2016).

[19] Song, L., Falzone, N. \& Vallis, K. A. EGFcoated gold nanoparticles provide an efficient nano-scale delivery system for the molecular radiotherapy of EGFR-positive cancer. Int. J. Radiat. Biol.92, 716-723 (2016).

[20] Wang, A. Z., Langer, R. \& Farokhzad, O. C. 
Nanoparticle delivery of cancer drugs. Annu. Rev. Med.63, 185-198 (2012).

[21] Singh, R. \& Lillard Jr, J. W. Nanoparticlebased targeted drug delivery. Exp. Mol. Pathol.86, 215-223 (2009).

[22] Rizvi, S. A. A. \& Saleh, A. M. Applications of nanoparticle systems in drug delivery technology. Saudi Pharm. J.26, 64-70 (2018).

[23] Kamei, K. et al. Integrated heart/cancer on a chip to reproduce the side effects of anticancer drugs in vitro. RSC $A d v .7,36777-$ 36786 (2017).

[24] Hopper-Borge, E. A. et al. Mechanisms of tumour resistance to EGFR-targeted therapies. Expert Opin. Ther. Targets13, 339-362 (2009).

[25] Morgillo, F., Martinelli, E., Troiani, T., Tortora, G. \& Ciardiello, F. Combination of anti-egfr drugs and other molecular targeted agents as anti-cancer strategy. Curr. Cancer Ther. Rev.3, 117-126 (2007).

[26] Morgillo, F., Bareschino, M. A., Bianco, R., Tortora, G. \& Ciardiello, F. Primary and acquired resistance to anti-EGFR targeted drugs in cancer therapy. Differentiation 75 , 788-799 (2007).

[27] Cuneo, K. C., Nyati, M. K., Ray, D. \& Lawrence, T. S. EGFR targeted therapies and radiation: Optimizing efficacy by appropriate drug scheduling and patient selection. Pharmacol. Ther.154, 67-77 (2015).

[28] Skroński, M., Szpechciński, A. \& Chorostowska-Wynimko, J. Current methods to detect EGFR gene mutations as predictive factor for targeted therapies in non-small cell lung cancer - is there a ,golden standard" in diagnostics? Adv. Respir. Med.82, 311-322 (2014).

[29] Thassu, D., Deleers, M. \& Pathak, Y. V. Nanoparticulate drug delivery systems. 166, (CRC Press, 2007).

[30] Wilczewska, A. Z., Niemirowicz, K., Markiewicz, K. H. \& Car, H. Nanoparticles as drug delivery systems. Pharmacol. Reports64, 1020-1037 (2012).

[31] Langer, R. Drug delivery and targeting. NATURE-LONDON- 5-10 (1998).

[32] Zeng, L., Qin, C., Wang, W., Chi, W. \& Li,
W. Absorption and distribution of chitosan in mice after oral administration. Carbohydr. Polym.71, 435-440 (2008).

[33] Yan, C. et al. 5 $\beta$-Cholanic Acid/Glycol Chitosan Self-Assembled Nanoparticles (5 $\beta$-CHA/GC-NPs) for Enhancing the Absorption of FDs and Insulin by Rat Intestinal Membranes. AAPS PharmSciTech20, 30 (2019).

[34] $\mathrm{Pi}$, J.et al. Anano-cocrystal strategy to improve the dissolution rate and oral bioavailability of baicalein. Asian J. Pharm. Sci.14, 154-164 (2019).

[35] Nascimento, A. V. et al. Overcoming cisplatin resistance in non-small cell lung cancer with Mad2 silencing siRNA delivered systemically using EGFR-targeted chitosan nanoparticles. Acta Biomater.47, 71-80 (2017).

[36] Tsai, W., Yu, K., Huang, Y.-C. \& Lee, C.I. EGFR-targeted photodynamic therapy by curcumin-encapsulated chitosan/TPP nanoparticles. Int. J. Nanomedicine13, 903 (2018).

[37] Jin, H. et al. EGFR-targeting PLGA-PEG nanoparticles as a curcumin delivery system for breast cancer therapy. Nanoscale 9 , 1636516374 (2017).

[38] Yan, J. et al. Co-delivery of docetaxel and curcumin prodrug via dual-targeted nanoparticles with synergistic antitumour activity against prostate cancer. Biomed. Pharmacother. 88, 374-383 (2017).

[39] He, H., Markoutsa, E., Zhan, Y., Zhang, J. \& $\mathrm{Xu}, \mathrm{P}$. Mussel-inspired PLGA/polydopamine core-shell nanoparticle for light induced cancer thermochemotherapy. Acta Biomater.59, 181191 (2017).

[40] Clemons, T. D. et al. Distinction Between Active and Passive Targeting of Nanoparticles Dictate Their Overall Therapeutic Efficacy. Langmuir34, 15343-15349 (2018).

[41] Cui, X. et al. Enhanced Chemotherapeutic Efficacy of Paclitaxel Nanoparticles Codelivered with MicroRNA-7 by Inhibiting Paclitaxel-Induced EGFR/ERK pathway Activation for Ovarian Cancer Therapy. ACS Appl. Mater. Interfaces10, 7821-7831 (2018). [42] Gill, M. R. et al. 111 In-labelled polymeric 
nanoparticles incorporating a rutheniumbased radiosensitizer for EGFR-targeted combination therapy in oesophageal cancer cells. Nanoscale 10, 10596-10608 (2018).

[43] Ndagi, U., Mhlongo, N. \& Soliman, M. E. Metal complexes in cancer therapy-an update from drug design perspective. Drug Des. Devel. Ther.11, 599 (2017).

[44] Sharma, H., Mishra, P. K., Talegaonkar, S. \& Vaidya, B. Metal nanoparticles: a theranostic nanotool against cancer. Drug Discov. Today20, 1143-1151 (2015).

[45] Yao, C., Rudnitzki, F., Huettmann, G., Zhang, Z. \& Rahmanzadeh, R. Important factors for cell-membrane permeabilization by gold nanoparticles activated by nanosecond-laser irradiation. Int. J. Nanomedicine12, 5659 (2017).

[46] Bhattacharjee, T. T. et al. FTIR study of secondary structure changes in Epidermal Growth Factor by gold nanoparticle conjugation. Biochim. Biophys. Acta (BBA)General Subj.1862, 495-500 (2018).

[47] Ashton, J. R., Gottlin, E. B., Patz Jr, E. F., West, J. L. \& Badea, C. T. A comparative analysis of EGFR-targeting antibodies for gold nanoparticle CT imaging of lung cancer. PLoS One13, e0206950 (2018).

[48] Cho, S. K. et al. Multifunctional nanoclusters of NaYF4: Yb3+, Er3+ upconversion nanoparticleand gold nanorod for simultaneous imaging and targeted chemotherapy of bladder cancer. Mater. Sci. Eng. C97, 784-792 (2019).

[49] Groysbeck, N. et al. Synthesis and biological evaluation of $2.4 \mathrm{~nm}$ thiolate-protected gold nanoparticles conjugated to Cetuximab for targeting glioblastoma cancer cells via the EGFR. Nanotechnology30, 184005 (2019).

[50] $\mathrm{Mu}, \mathrm{X}$. et al. EGFR-targeted delivery of DOX-loaded Fe3O4@ polydopamine multifunctional nanocomposites for MRI and antitumour chemo-photothermal therapy. Int. J. Nanomedicine 12, 2899 (2017).

[51] Chen, H.-L. et al. Identification of epidermal growth factor receptor-positive glioblastoma using lipid-encapsulated targeted superparamagnetic iron oxide nanoparticles in vitro. J. Nanobiotechnology15, 86 (2017).
[52] Lu, Q.etal. Fe3O4@Au composite magnetic nanoparticles modified with cetuximab for targeted magneto-photothermal therapy of glioma cells. Int. J. Nanomedicine 13, 2491 (2018).

[53] Bai, K.-J., Chuang, K.-J., Ma, C.-M., Chang, T.-Y. \& Chuang, H.-C. Human lung adenocarcinoma cells with an EGFR mutation are sensitive to non-autophagic cell death induced by zinc oxide and aluminium-doped zinc oxide nanoparticles. J. Toxicol. Sci.42, 437-444 (2017).

[54] Li, B., Jiang, Z., Xie, D., Wang, Y. \& Lao, $\mathrm{X}$. Cetuximab-modified $\mathrm{CuS}$ nanoparticles integrating near-infrared-II-responsive photothermal therapy and anti-vessel treatment. Int. J. Nanomedicine13, 7289 (2018).

[55] $\mathrm{Pi}$, J. et al. GE11 peptide conjugated selenium nanoparticles for EGFR targeted oridonin delivery to achieve enhanced anticancer efficacy by inhibiting EGFR-mediated PI3K/ AKT and Ras/Raf/MEK/ERK pathways. Drug Deliv.24, 1549-1564 (2017).

[56] Huang, J. et al. Highly Uniform Synthesis of Selenium Nanoparticles with EGFR Targeting and Tumour Microenvironment Responsive Ability for Simultaneous Diagnosis and Therapy of Nasopharyngeal Carcinoma. ACS Appl. Mater. Interfaces (2019).

[57] Kim, J. S. et al. Tumour-specific delivery of therapeutic siRNAs by anti-egFr immunonanoparticles.Int.J. Nanomedicine13, 4817 (2018).

[58] Liang, Y. et al. Smart nanoparticles assembled by endogenous molecules for siRNA delivery and cancer therapy via CD44 and EGFR dualtargeting. Nanomedicine Nanotechnology, Biol. Med.15, 208-217 (2019).

[59] Faucon, A. et al. Bioconjugated fluorescent organic nanoparticles targeting EGFRoverexpressing cancer cells. Nanoscale9, 18094-18106 (2017).

[60] Chen, G., Wang, Y., Xie, R. \& Gong, S. Tumour-targeted $\mathrm{pH} /$ redox dual-sensitive unimolecular nanoparticles for efficient siRNA delivery. J. Control. Release 259, 105114 (2017). 
[61] Zhang,Z.etal.Anti-EGFR-iRGDrecombinant protein modified biomimetic nanoparticles loaded with gambogic acid to enhance targeting and antitumour ability in colorectal cancer treatment. Int. J. Nanomedicine13, 4961 (2018).

[62] Zhai, J. et al. Paclitaxel-loaded selfassembled lipid nanoparticles as targeted drug delivery systems for the treatment of aggressive ovarian cancer. ACS Appl. Mater. Interfaces 10, 25174-25185 (2018).

[63] Zhou, J. et al. PLAUR confers resistance to Gefitinib through EGFR/P-AKT/Survivin signaling pathway. Cell. Physiol. Biochem.47, 1909-1924 (2018). 